\title{
ControlHarvest: Ensino de Ecologia por Meio de Gamificação do Controle Biológico
}

\author{
Gabriel Alves, Patrick Warley, João Quadros, \\ Leonardo Lignani, Eduardo Ogasawara \\ EIC - Escola de Informática \& Computação \\ Centro Federal de Educação Tecnológica Celso Suckow da Fonseca - CEFET/RJ ${ }^{1}$ \\ \{jquadros, leolignani, eogasawara\}@cefet-rj.br
}

\begin{abstract}
Biological control is a strategy used to control pests (insects, diseases) for certain environments, such as farmland. It is based on methods for controlling pests using other living beings. However, studies must be conducted before this practice in order to reduce possible side effects. With these concepts in mind, we developed an educational game that enhances the understanding of aspects of the ecology of populations, functions of biological control and specificity of some ecological relationships. This game is called ControlHarvest and uses a simplified scenario of running a farm. The result is a game that tries to introduce concepts related to ecology in a ludic way. The game was evaluated with technical high school students. They found interest about the content covered by the game.
\end{abstract}

Resumo. Controle Biológico é uma estratégia utilizada para combater pragas (insetos, doenças) em certos ambientes, como campos agrícolas. Ele é baseado em métodos para controlar pragas usando outros seres vivos. Contudo, estudos devem ser conduzidos antes dessa prática de forma a diminuir possíveis efeitos colaterais. Com esses conceitos em mente, desenvolvemos um jogo educativo que explore aspectos da ecologia das populações, as funções do controle biológico e a especificidade de algumas relações ecológicas. Esse jogo chama-se ControlHarvest e se utiliza de um cenário simplificado de gestão de uma fazenda agrícola. O resultado é um jogo que tenta introduzir os conceitos ligados à ecologia de uma maneira lúdica. O jogo foi avaliado com alunos do ensino médio técnico. Eles observaram interesse a respeito do conteúdo abordado pelo jogo.

\section{Introdução}

A utilização de objetos educacionais digitais vem se tornando cada vez mais frequente no ensino de Biologia (Lima 2009). Esses recursos, muitas vezes, preenchem uma lacuna existente decorrente da dificuldade em se realizar atividades práticas. Áreas como evolução e ecologia, nas quais as observações de processos necessitam de escalas de tempo e espaço incompatíveis com o ambiente escolar, podem se beneficiar destas ferramentas.

\footnotetext{
${ }^{1}$ Os autores agradecem ao CNPq e à FAPERJ pelo financiamento parcial do trabalho.
} 
A adoção de programas simuladores com técnicas de condução (do inglês, steering) (Mattoso et al. 2013) no ensino de ecologia pode ser uma opção interessante, uma vez que as simulações possuem componentes visuais e interativos (como variáveis de valor alterável) que permitem ao utilizador mexer no simulador e compreender melhor suas características.

Um simulador é uma ferramenta bem adaptada ao aprendizado via descoberta o que faz com que o ensino e instrução por simulador sejam incluídos na categoria do aprendizado construtivista (Jong e Joolingen 1998). Essa abordagem enfatiza fortemente o aluno como elemento ativo no processo de aquisição de conhecimento. A principal tarefa no ensino por simulador é a inferência de características do modelo subjacente à simulação por meio de experimentação. Esses mesmos simuladores ficam mais atrativos quando assumem a forma de jogos. Mantidas suas características de aprendizado por descoberta, eles podem ganhar maior potencial educacional ao tornam o ensino mais prazeroso (Lee e Hammer 2011).

$\mathrm{O}$ uso de simulador pode ser ainda mais interessante quando adotado em uma perspectiva de gamificação. Gamificação (Gamification) é um termo criado por Nick Pelling para designar o uso de pensamento lúdico e de mecânica de jogos em contextos diferentes (Kapp 2012). Mecânicas como a adição de uma narrativa ou de elementos colecionáveis por parte do usuário, como as utilizadas em jogos de interpretação de personagens (RPGs, do inglês Role-playing game), são algumas técnicas usadas na gamificação. Tais técnicas se utilizam dos desejos naturais dos usuários, tais como conquista, autoexpressão e altruísmo, para recompensar determinadas ações do jogador.

Este projeto tem como objetivo criar um jogo baseado nas mecânicas de uma simulação. Intitulado de "ControlHarvest", o jogo ocorre em um ambiente no qual o jogador precisa utilizar o controle biológico em uma plantação para impedir que pragas comam todas as suas plantas. Utilizando o tema do controle biológico, esperamos que ControlHarvest funcione como uma introdução lúdica à aprendizagem de ecologia, abordando conceitos como a relação predador-presa, introdução de espécies em ecossistemas e capacidade suporte do ambiente. No presente artigo, relatamos os resultados de uma avaliação experimental preliminar, discutindo as potencialidades e limitações do jogo criado.

Além desta introdução, este trabalho é dividido em mais cinco seções. Na seção 2 são apresentados os conceitos de controle biológico e a relação com o ensino de Ecologia. Na seção 3 são apresentados trabalhos relacionados ao tema. Na seção 4 é apresentado a concepção do jogo ControlHarvest. Os métodos e resultados preliminares da avaliação experimental aparecem na seção 5 e, finalmente, algumas conclusões e perspectivas são apontadas na seção 6 .

\section{Controle Biológico e Ensino de Ecologia}

A prática do controle biológico (CB) pode ser compreendida como o controle de populações de espécies que ocasionam danos à agricultura (ou ao ambiente, de forma geral) por meio da utilização de outras espécies de seres vivos (Handelsman e Stabb 1996). Os agentes controladores são predadores, parasitas ou agentes patogênicos que ataquem naturalmente os insetos ou outras espécies que se deseja controlar (as 
populares "pragas"). Espécies utilizadas como agentes controladores costumam ser invertebrados como, por exemplo, vespas, besouros ou ácaros.

Existem três tipos de estratégias para aplicação do CB: importação, acréscimo e conservação (Landis e Orr 1996). A "importação" ocorre quando agentes controladores exóticos são artificialmente introduzidos a um novo habitat. O "acréscimo" ocorre quando uma população de agentes nativos recebe um aumento suplementar em sua população. "Conservação" é a manutenção de agentes já existentes no meio.

O CB também pode ter efeitos negativos na biodiversidade. Isso ocorre quando o predador, parasita ou agente patogênico ataca uma espécie diferente da espécie alvo. Esse fenômeno é comum quando são usados agentes de controle generalistas, ou seja, que não predam apenas uma determinada presa.

Atualmente, as espécies controladoras importadas normalmente passam por um processo que engloba baterias de estudos e testes. Após determinar qual é o inimigo natural de determinada praga, este inimigo é rigorosamente avaliado, testado e posto em quarentena para garantir que sua introdução no meio seja capaz de funcionar. Se a espécie passar por essa triagem, então, será produzida em massa e solta no meio natural, com posteriores avaliações de efetividade.

A temática do controle biológico permite trabalhar com uma grande diversidade de conceitos ecológicos. Introdução de espécies, relação predador-presa, crescimento populacional, capacidade suporte do ambiente são exemplos de conceitos operacionalizados no entendimento deste complexo processo de manejo agrícola. A diversidade de conceitos abordados amplia as potencialidades do uso educativo, justificando a escolha da temática do controle biológico para o jogo.

\section{Trabalhos Relacionados}

Os modelos matemáticos normalmente utilizados para descrever fenômenos de presapredador podem ser utilizados na modelagem de uma situação de CB. As equações de Lotka-Volterra, por exemplo, são equações diferenciais, não-lineares, de primeira ordem usadas para descrever sistemas biológicos e transmissão de biomassa. As espécies, segundo as equações, tomam formas de produtor-consumidor ou parasitahospedeiro (Begon 2006). Este modelo faz uma série de suposições sobre o ambiente e a evolução das populações de presas e predadores, tais como: (i) a população de presas encontra alimento o tempo todo, (ii) o suprimento de alimentos do predador depende da população de presas, (iii) a taxa de mudança da população é proporcional ao seu tamanho, (iv) o ambiente não muda a favor de uma espécie. Contudo, no problema utilizado em nossa proposta para CB, as suposições (i) e (iv) do Modelo Lotka-Volterra não são garantidas. A quantidade de comida da presa no jogo é limitada pela plantação do jogador, o que interfere na taxa de reprodução do mesmo. A redução de área de plantação, afeta a movimentação das presas. Por estes motivos o modelo de equações Lotka-Volterra não é diretamente aplicável ao nosso jogo.

A utilização de simuladores computacionais na avaliação da dinâmica de populações para casos reais de controle biológico não é uma novidade (Ternes et al. 2005). Entretanto, em um levantamento prévio, não encontramos nenhum jogo ou simulador computacional com finalidade educativa que trabalhasse esta temática, o que justifica a originalidade desta proposta. Existem jogos computacionais que abordam 
questões ecológicas, como o jogo Calango, no qual o jogador controla um lagarto cujo objetivo é sobreviver em um ambiente da caatinga (Loula et al. 2009). A perspectiva ecológica deste jogo é a interação do organismo com o ambiente, enquanto que, no ControlHarvest, é adotada a perspectiva de interação entre populações.

Sobrinho e Borges (2010) e Figueiredo et al (2011) relatam a utilização de simuladores computacionais de dinâmicas populacionais com finalidades educativas. Sobrinho e Borges (2010) abordam os mecanismos de transmissão e evolução de uma epidemia, enquanto Figueiredo et al (2011), as atividades de uma colmeia. Ao contrário de ControlHarvest, estes simuladores de dinâmica populacional não incorporam fatores como ludicidade, interatividade, objetivos a serem alcançados ou motivação do usuário, não podendo ser analisados dentro da perspectiva de jogos educacionais.

\section{ControlHarvest: o Jogo}

O ControlHarvest é um jogo de CB que tem como enredo a gestão de fazenda. Dessa forma, com o objetivo de proporcionar uma experiência de usabilidade que torne o aprendizado de CB mais lúdico para o usuário, nos inspiramos em jogos já existentes, como Harvest Moon (Rising Star 2013) e Infectonator 2 (Kongregate 2013). O jogador explora os elementos de estratégia como: qual predador comprar para combater uma dada praga, ou, que planta possui mais resistência as pragas ou mais lucro ao ser vendido, favorecendo o avanço no jogo.

Mesmo que de forma superficial, a gamificação proposta para ControlHarvest insere o jogador em questões relativas as noções de CB. A estratégia de $\mathrm{CB}$ que o jogador pode utilizar é a de importação e acréscimo, isto é, a soltura suplementar de novos predadores que comam as pragas. Tais predadores são acrescentados pelo jogador a partir da interface do jogo, simulando a ação do ser humano ao introduzir uma espécie em um novo nicho ecológico.

O jogo transcorre em um ambiente que apresenta a fazenda em um perspectiva espacial 2D. Esta perspectiva corresponde ao mapa do jogo. Cada mapa representa o cenário em que o jogador realiza uma ação, ou seja, é uma fazenda atacada por pragas. Nesses mapas, o jogador seleciona os predadores e plantas que deseja comprar. Ainda, é nele que as pragas, predadores e plantas interagem dando forma ao jogo. Conforme apresentado na Figura 1, a praga, o predador, o capital e as plantas são representados pelas setas verde, azul, cinza e laranja, respectivamente.

O jogo foi concebido utilizando o Greenfoot (Greenfoot 2012) como motor de execução. Esse motor foi escrito em Java e ensina essa linguagem a partir da interação de objetos. O estilo de jogo para a gamificação foi o modelo de gestor de fazenda. Já existiam alguns outros jogos de gestão, baseados em outros temas, os quais o ControHarvest podia se inspirar. Além disso, o Greenfoot facilita a programação de um jogo deste tipo por ser um motor que favorece a movimentação de imagens bidimensionais.

O ControHarvest está disponível no Sourceforge ${ }^{2}$. As etapas da implementação foram: a adaptação das ideias de $\mathrm{CB}$, o projeto da mecânica do jogo, a implementação

\footnotetext{
${ }^{2}$ http://sourceforge.net/p/gpca/wiki/ControlHarvest
} 
da mecânica e implementação da interface gráfica. Houve, ainda, a escolha de quais tipos de pragas e predadores estariam presentes na interface e a relação geral entre eles. Dado que o jogo é apenas uma referência ao processo real de $\mathrm{CB}$, as pragas e predadores utilizados são espécies fictícias, representadas por figuras artísticas.

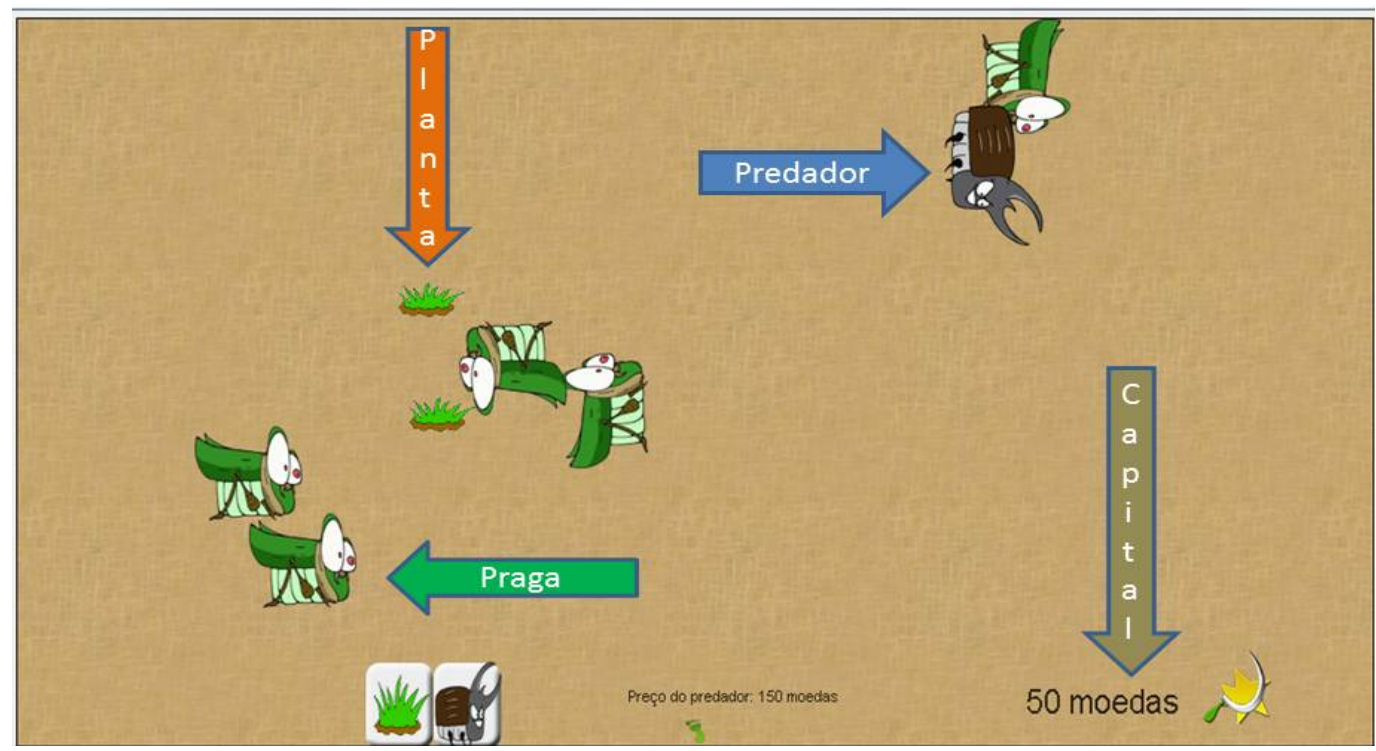

Figura 1 Tela do ControlHarvest

A mecânica de gestão é simples e exclui o uso do teclado, permitindo que toda a interação do jogo seja feita pelo mouse. Todas as ações de compra de sementes e predadores, assim como seu plantio ou liberação no mapa, acontece por simples cliques. Isso facilita a experiência do jogador que pode se concentrar mais nos detalhes que acontecem na tela sem ter que memorizar uma série de comandos e atalhos diferentes. $\mathrm{O}$ foco da mecânica é o processo de controle de pragas e administração de capital que o jogador possui. O jogador toma a decisão de qual predador ele deve liberar de forma a não esgotar seu capital e a combater as pragas apropriadamente. Além disso, o jogador deve ser capaz de progredir, habilitando plantas que proporcionem mais lucro. $\mathrm{O}$ cenário básico de Game Over ocorre quando as pragas dominam a área de plantação e não há mais dinheiro para replantio e nem para introduzir predadores.

Um segundo cenário de Game Over ocorre quando o predador, por si só, se torna uma praga. Isso pode acontecer quando uma quantidade grande de insetos predadores é solta no mapa do jogo. Esse cenário é interessante porque simula algo que pode acontecer em ambientes onde o $\mathrm{CB}$ é aplicado, no qual uma espécie que deveria controlar pragas acaba se tornando uma praga.

Também com o objetivo de auxiliar o aprendizado, foram adicionadas funcionalidades interessantes ao gestor de fazenda, como um gráfico populacional. Dado que o jogo trata da relação entre um predador e uma praga é interessante que o jogador possa observar o crescimento ou decrescimento da população, especialmente de seus agentes controladores (os predadores). Isso permite que o jogador entenda quando esta se aproximando de uma situação de fim de jogo onde seu dinheiro acabou e sua população de predadores está perto de ser extinta. 


\section{Avaliação Experimental}

\subsection{Metodologia}

A avaliação experimental foi baseada na utilização do jogo por usuários em um experimento piloto. Participaram da avaliação catorze alunos do ensino médio/técnico integrado do CEFET/RJ, número que consideramos suficiente por se tratar de uma avaliação exploratória das potencialidades do jogo. Estes alunos não haviam estudado anteriormente o tópico "controle biológico" em aulas do ensino médio. O objetivo da avaliação experimental foi (i) avaliar a contribuição do jogo ControlHarvest na aprendizagem de conceitos ecológicos e, mais especificamente, sobre a prática do $\mathrm{CB}$, (ii) analisar a usabilidade e as percepções dos estudantes em relação ao jogo e (iii) detectar possíveis problemas na execução do jogo e na utilização do questionário para uma futura avaliação.

O experimento foi realizado no Laboratório de Jogos Educacionais da Escola de Informática \& Educação do CEFET/RJ. Foi disponibilizado uma versão do ControlHarvest em cada desktop do laboratório, no qual os alunos puderam experimentar o jogo. Em média, o experimento de cada aluno durou aproximadamente 40 minutos. Uma vez conduzido o experimento, os alunos preencheram o formulário de avaliação, criado no Google Forms (Google 2014). O formulário era composto de 23 questões que avaliavam o potencial de aprendizagem e de aspecto lúdico do jogo. As respostas dos formulários foram exportadas para o formato Excel, sendo os dados brutos pré-processados para que a análise pudesse ser realizada. $\mathrm{O}$ formulário juntamente com os dados brutos estão disponíveis na página do ControlHarvest.

Para análise do potencial de aprendizagem do jogo, foi solicitado que cada estudante realizasse a avaliação ("concordo" ou "discordo") de quatro afirmativas propostas (Figura 2). Assumimos que a avaliação das afirmativas estava sendo realizada com base em conhecimentos prévios e na experiência do jogo, uma vez que estes estudantes não trabalharam estes conceitos em aulas formais prévias à realização do experimento. A correta avaliação de uma afirmativa seria um indício de que o estudante conseguiu compreender um princípio ecológico e incorporá-lo à sua estrutura cognitiva sobre o assunto, o que nos permitiu elaborar hipóteses acerca do potencial de aprendizagem em ControlHarvest. Também foi solicitado que o aluno indicasse, por meio de comentários abertos, que situação vivenciada durante o jogo havia influenciado a sua resposta à questão anterior. Estes relatos contribuíram para a análise do padrão de resposta para cada afirmativa.

Para avaliar as percepções dos estudantes, foi solicitado aos participantes que enumerassem, em uma escala de 1-5, (i) qual nota eles dariam ao jogo, (ii) o quanto eles avaliavam que haviam aprendido com o jogo e (iii) o quanto eles se divertiram com o jogo. Avaliações 5-4 foram consideradas como positivas, 3 como regular e 1-2 como negativas. Também foi incluída uma opção para a sugestão de novas mecânicas que poderiam ser incorporadas futuramente.

\subsection{Resultados preliminares}

A maioria dos alunos corretamente discordou das afirmativas A e C (Figura 2). No primeiro caso, o fato da espécie introduzida como agente controlador poder ter sua população aumentada em grande número foi determinante para a percepção dos 
estudantes de que o controle biológico pode ter efeitos negativos. Os seguintes relatos corroboram esta ideia:

"Durante a partida, o número dos predadores cresceu muito mais que o de pragas. Provando assim que com o aumento da nova espécie, podem ocorrer, talvez, iguais impactos ambientais."(aluno 1)

"Houve impacto ambiental sim, pois a espécie controladora saiu de controle se proliferando de tal forma que não tivemos mais como controlar sua população dentro do ecossistema exposto no jogo.”(aluno 8)

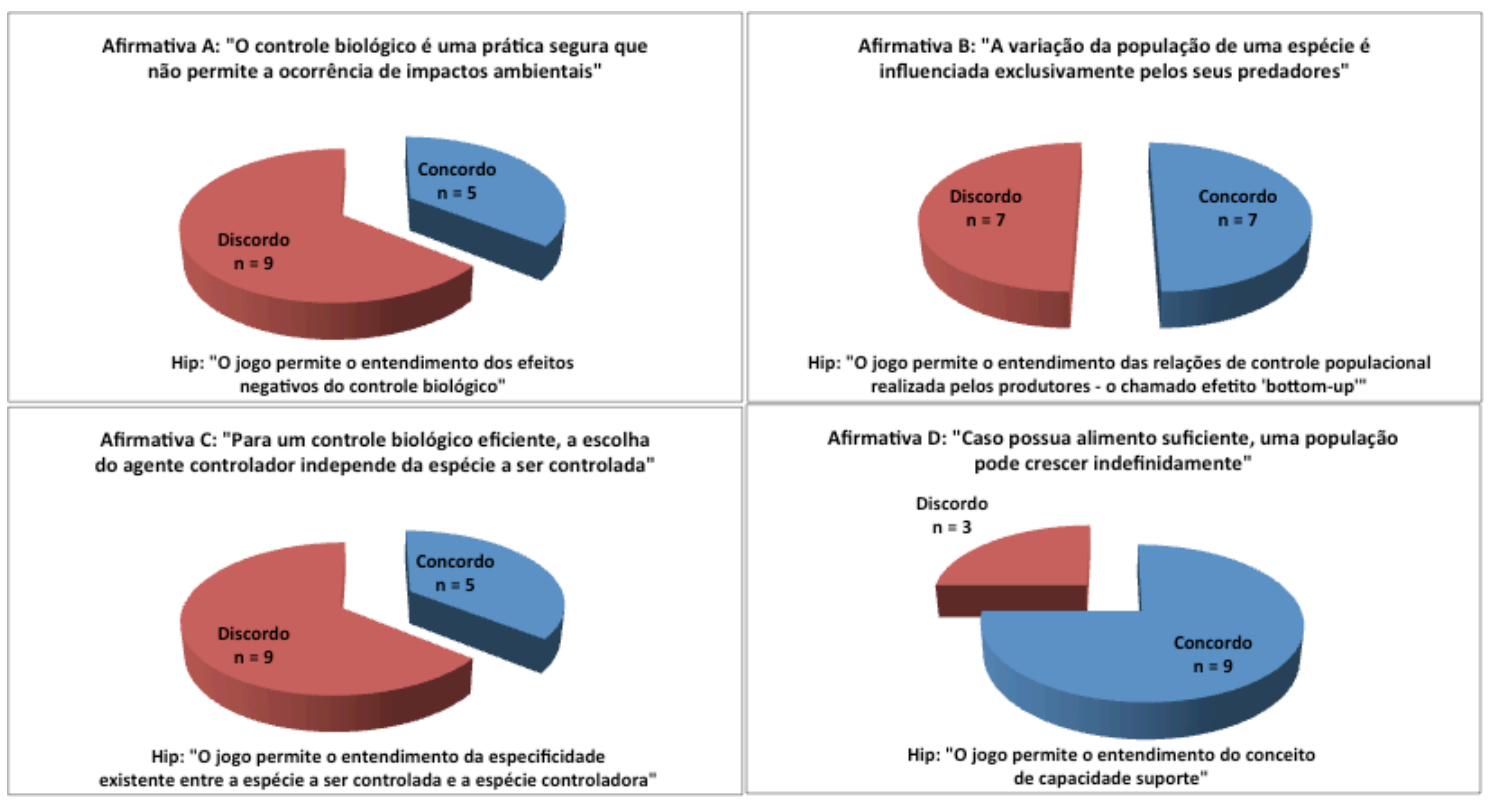

Figura 2 Afirmativas propostas e a resposta dos estudantes às questões relacionadas a contribuição do jogo ${ }^{3}$

A afirmativa $C$ trabalha a questão da especificidade existente entre a espécie que deve atuar como agente controlador e a espécie que deve ser controlada. A maioria dos estudantes corretamente percebeu que as taxas de captura não eram as mesmas para os diferentes insetos predadores, ou seja, cada uma se alimentava de espécies determinadas, como podemos ver nos seguintes relatos:

"No jogo após colocados besouros 2 espécies de praga somem, porém duas permanecem. Uma provável explicação para isso é justamente não ter sido escolhido o predador certo para essas pragas que não foram contidas."(aluno 1)

"A joaninha só comia uma determinada espécie de bichinhos e o besouro também. portanto na hora de escolher o besouro e a joaninha tínhamos que ver qual bichinho estava em predominância."(aluno 6)

"se eu por [sic] somente joaninha os alimentos do besouro vão procriar e você vai perder"(aluno 12)

\footnotetext{
${ }^{3}$ Abaixo de cada gráfico são apresentadas as hipóteses que estão sendo analisadas. Estas hipóteses serão testadas posteriormente, quando o número de aplicações do jogo permitir o correto tratamento estatístico.
} 
Houve dificuldade em avaliar corretamente a afirmativa B, como podemos deduzir pelo equilíbrio no número de alunos que concordaram e discordaram da afirmativa (Figura 2). Podemos interpretar esta tendência como um indício de que a proposta do jogo ControlHarvest está muito focada na relação predador-presa entre os animais, o que pode provocar uma impressão equivocada de que as espécies produtoras do ecossistema (neste caso, as plantas), não participam da regulação populacional. Os relatos dos alunos que concordaram com a afirmativa corroboram esta ideia, como podemos ver a seguir:

"quanto mais predadores tinha [sic], menor seria a população dos invasores" (aluno2)

\section{“quanto mais predador menos o animal aparece”(aluno 12)}

Deve ser destacado que existe a potencialidade de se trabalhar esta questão com pequenos ajustes no jogo. Alguns alunos que discordaram da afirmativa $\mathrm{C}$ corretamente apontaram que:

"A variação dessa população também tem relação com a quantidade de alimento."(aluno 1)

“As plantas também influenciam nos insetos que aparecem"(aluno 11)

$\mathrm{Na}$ afirmativa $\mathrm{D}$, praticamente a totalidade dos alunos concordou com a proposição (Figura 2). Este resultado preliminar indica que ao jogar ControlHarvest, um aluno pode adquirir a falsa impressão de que populações de organismos podem crescer sem qualquer limite, estando este crescimento limitado exclusivamente pela oferta de alimento. Desconsidera-se assim a existência de outros fatores limitantes, como o espaço e a própria taxa de mortalidade dos organismos. Os seguintes relatos reforçam esta impressão:

"quanto mais alimento você possuir, mais predadores você terá" (aluno 2)

"Quanto mais o animal se alimenta, mais ele se reproduz" (aluno 7)

A Figura 3 traz os resultados preliminares em relação às impressões dos estudantes e a usabilidade do jogo. A maior parte dos alunos fez uma avaliação positiva do jogo (nota atribuída de 4 ou 5). A avaliação geral de ControlHarvest aparentemente está mais relacionada a percepção do divertimento que o jogo proporciona - e não a percepção da aprendizagem - uma vez que o padrão de resposta à pergunta sobre divertimento é similar ao da nota atribuída. Alguns jogadores notaram falhas de aspecto técnico como a falta de um mecanismo de remoção de agentes controladores. Outros sugeriram algumas teclas de atalho e ainda novas variedades de plantas. Um dos alunos também indicou que as informações sobre as presas, predadores e plantas não estavam muito visíveis. 


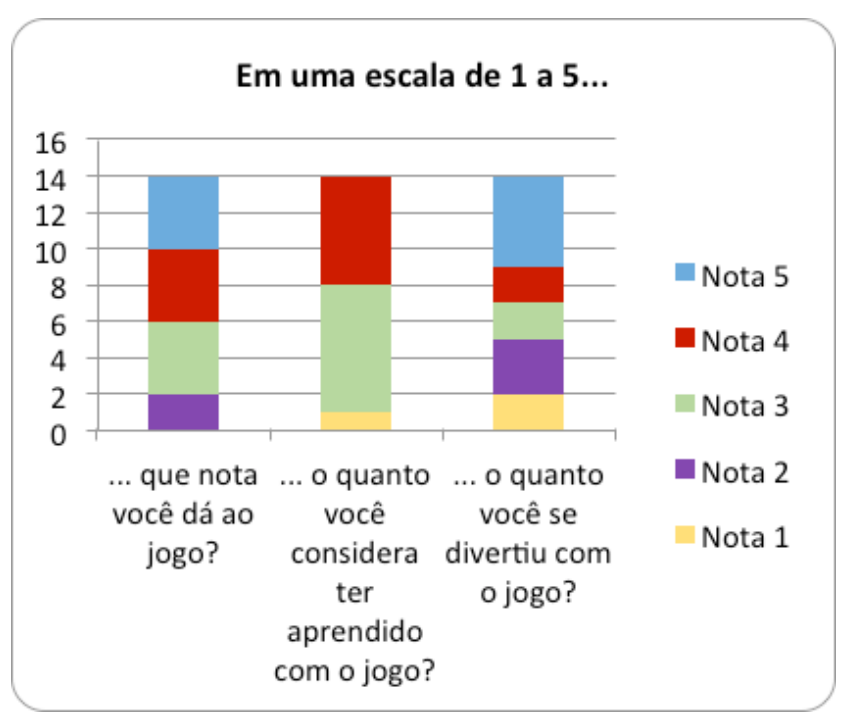

Figura 3 Avaliação da percepção dos estudantes em relação ao ControlHarvest

\section{Conclusões e perspectivas}

A realização de atividades práticas no ensino de Ecologia nem sempre é possível, em função da necessidade de se trabalhar em escalas de tempo e espaço fora da realidade escolar. Em função desta complexidade, o objetivo deste trabalho foi elaborar o jogo educacional ControlHarvest, que utiliza a temática de CB para explorar conceitos ecológicos relevantes. O ControlHarvest foi desenvolvido em Java e usou o motor de criação de jogos Greenfoot. Em termos de enredo, o jogo se inspira na experiência de gestão de uma fazenda, relacionando a realização de uma colheita bem sucedida com a necessidade de CB feito de modo adequado.

Foi feita uma avaliação experimental preliminar para identificar pontos nos quais a abordagem pareça ser adequada. Os resultados experimentais foram promissores. Após jogar ControlHarvest e utilizando seus conhecimentos prévios, os estudantes conseguiram perceber os efeitos negativos do $\mathrm{CB}$ e a relação de especificidade que pode existir entre predador-presa. Modificações precisam ser realizadas a fim de explorar melhor os conceitos de capacidade suporte e do controle do crescimento populacional. É possível também que um tutorial (ou animações) embutido ao jogo possa facilitar a apresentação dos conceitos, chamando a atenção para diferentes fenômenos que ocorrem durante a partida. Ainda, a adição de teclas de atalhos e mecanismos de remoção de pragas permitiria uma melhor experiência de jogo para os alunos. A utilização do jogo associada a um contexto de discussão em sala de aula ainda será avaliada, mas poderá resultar em um uso mais efetivo das suas potencialidades.

\section{Referências}

Begon, M., (2006), Ecology: From Individuals to Ecosystems. 4 edition ed. Place of publication not identified, Wiley-Blackwell.

Figueiredo, J. E. M., da Silva, A. S., Werneck, V. M. B., da Costa, R. M. E. M., (2011), "Sim-Colmeia: Ambiente de simulação da dinâmica populacional de uma colmeia para o ensino de Biologia". In: XXII Simpósio Brasileiro de Informática na Educação 
Google, (2014), Google Forms, http://www.google.com/google-d-s/createforms.html.

Greenfoot, (2012), Greenfoot homepage, http://www.greenfoot.com.

Handelsman, J., Stabb, E. V., (1996), "Biocontrol of Soilborne Plant Pathogens", The Plant Cell, v. 8, n. 10 (out.), p. 1855.

Jong, T. D., Joolingen, W. R. V., (1998), "Scientific Discovery Learning with Computer Simulations of Conceptual Domains", Review of Educational Research, v. 68, n. 2 (jun.), p. 179-201.

Kapp, K. M., (2012), The gamification of learning and instruction: game-based methods and strategies for training and education. San Francisco, CA, Pfeiffer.

Kongregate,

Infectonator

2 , http://www.kongregate.com/games/TogeProductions/infectonator-2.

Landis, D. A., Orr, D. B., (1996), Biological Control: Approaches and Applications, http://ipmworld.umn.edu/chapters/landis.htm.

Lee, J. J., Hammer, J., (2011), "Gamification in Education: What, How, Why Bother?", Academic Exchange Quarterly, v. 15, n. 2, p. 2.

Lima, L. de, (2009), "Ensino de Conceitos Biológicos: a Relação entre Aprendizagem Significativa e Objetos Educacionais Digitais". In: XX Simpósio Brasileiro de Informática na Educação

Loula, A. C., Oliveira, E., Muñoz, Y. J., Vargens, M. M., Apolinário Jr, A., El-Hani, C., Silva, L., Rocha, P., (2009), "Modelagem ambiental em um jogo eletrônico educativo". In: VIII Brazilian Symposium on Games and Digital Entertainment. Rio de Janeiro: SBGames, p. 171-180

Mattoso, M., Ocaña, K., Horta, F., Dias, J., Ogasawara, E., Silva, V., de Oliveira, D., Costa, F., Araújo, I., (2013), "User-steering of HPC workflows: state-of-the-art and future directions". In: Proceedings of the 2nd ACM SIGMOD Workshop on Scalable Workflow Execution Engines and Technologies (SWEET), p. 1-6, New York, NY, USA.

Rising Star, (2013), Harvest Moon, http://www.risingstargames.com/harvestmoon.aspx.

Sobrinho, M. M. S., Borges, A. T., (2010), "Aprendizagem sobre epidemias com simulações computacionais", Revista Brasileira de Ensino de Ciência e Tecnologia, v. 3, n. 1

Ternes, S., Fernandes, J. F. R., Yang, H. M., (2005), "Uso de Modelagem Matemática e Simulação na Avaliação do Controle Biológico da Minadora do Citros", Revista Brasileira de Agroinformática, v. 7, n. 2, p. 1-16. 